\title{
Treatment of hyperkalaemia with intravenous salbutamol
}

\author{
I A Murdoch, R Dos Anjos, G B Haycock
}

\begin{abstract}
Thirteen children with hypertalaemia were treated by intravenous infusions of salbutamol, $4 \mu \mathrm{g} / \mathrm{kg}$ over 20 minutes. Reductions in the mean (SD) plasma potassium concentrations, of $1.48(0.5)$ and $1.64(0.5) \mathrm{mmol} / \mathrm{l}$ were obtained at 40 and 120 minutes, respectively, after completion of the infusions. No side effects were noted.
\end{abstract}

Hyperkalaemia is conventionally defined as a plasma potassium concentration of greater than $5.5 \mathrm{mmol} / \mathrm{l}$ in children and adults and $6.0 \mathrm{mmol} / \mathrm{h}$ in the newborn. Because of its potentially lethal consequences, usually cardiac arrhythmias culminating in asystole, hyperkalaemia is a medical emergency demanding urgent treatment. Treatment should be rapid, predictable, and if possible have a sustained effect. Nebulised salbutamol has been reported to cause a fall in the plasma potassium concentration, ${ }^{1}$ and was once the recognised treatment for hyperkalaemic familial periodic paralysis. ${ }^{2}$ Salbutamol given intravenously has recently been shown to be effective in treating hyperkalaemia in adults with end stage renal failure. ${ }^{3}$ We report our experience with the use of intravenous infusions of salbutamol in 13 children with hyperkalaemia.

Patients and methods

Between July 1988 and December 1989, 13 children with hyperkalaemia were treated with sal- butamol by intravenous infusion to try and reduce their plasma potassium concentrations. Six infants had hyperkalaemia as a result of acute renal failure after cardiac surgery, and the remaining seven had a variety of renal disorders that culminated in hyperkalaemia (table).

All the children were anuric at the time that the salbutamol was given. None of the children with acute renal failure were receiving adrenaline but all were on low doses of dopamine $3 \mu \mathrm{g} /$ $\mathrm{kg} /$ minute and dobutamine, median dose $10 \mu \mathrm{g} /$ $\mathrm{kg} /$ minute. Before the infusion of salbutamol all patients received $10 \%$ calcium gluconate $(0.5$ $\mathrm{ml} / \mathrm{kg}$ ) as an intravenous infusion over five minutes with electrocardiographic monitoring to try and minimise the potential cardiotoxic effects of potassium.

Salbutamol was given in a dose of $4 \mu \mathrm{g} / \mathrm{kg}$ made up in $5 \mathrm{ml}$ water for injection and infused at a constant rate over 20 minutes with electrocardiographic monitoring. No tachyarrhythmias or other complications occurred.

The six infants with acute renal failure after cardiac surgery had a mean age of 0.24 years (range $0.01-0.5$ ), a mean weight of $4.0 \mathrm{~kg}$ (range 3.2-5.5), a mean serum creatinine concentration of $193 \mu \mathrm{mol} / 1$ (range 150-254), and a mean (SD) initial plasma potassium concentration of $6.7(0.14) \mathrm{mmol} / \mathrm{l}$ before treatment. The initial mean plasma potassium concentration of the group with underlying renal disease and hyperkalaemia $(n=7)$ was $6.7(0.34) \mathrm{mmol} / \mathrm{l}$. The mean age, weight, and plasma creatinine concentration of this group were $6 \cdot 1$ years
United Medical and Dental School of Guy's and St Thomas's Hospitals,

Guy's Tower,

Guy's Hospital

London SE1 9RT

Department of

Paediatric Cardiology

I A Murdoch

$R$ Dos Anjos

Department of Paediatric Nephrology

G B Haycock

Correspondence to:

Professor Haycock.

Accepted 9 December 1990

(Arch Dis Child 1991;66:527-8).

Details of patients studied

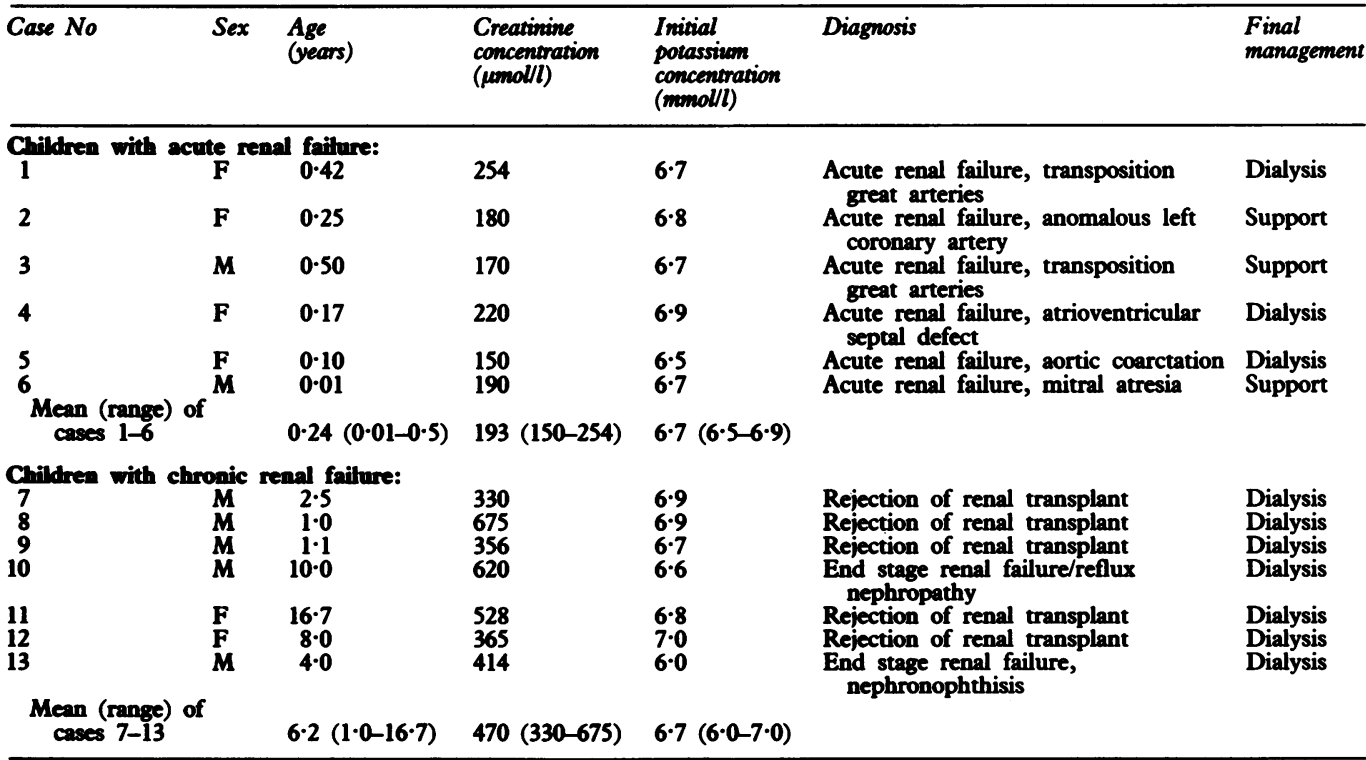




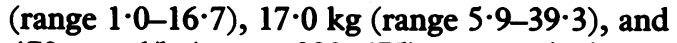
$470 \mu \mathrm{mol} / 1$ (range $330-675$ ), respectively, at the time of treatment.

The plasma potassium concentration was measured with an ion selective electrode (Hitachi 737). One millilitre of blood was withdrawn, placed in a lithium heparin tube, and sent immediately for analysis. In those patients with indwelling arterial lines, arterial blood was sampled. In the remainder venous blood was obtained by repeat venepuncture, care being taken to avoid haemolysis. Potassium was estimated consistently in either arterial or venous blood in each individual patient. Further measurements of the plasma potassium concentration were made at roughly 40 and 120 minutes after the salbutamol infusion had ceased in 13 and nine patients, respectively. Four children were excluded from further study at 120 minutes, three because peritoneal dialysis had been started and one because a Tenckhoff peritoneal catheter was being inserted.

Statistical analysis was by paired Student's $t$ test and a $p<0.05$ was accepted as significant. The results are expressed as mean (SD).

\section{Results}

The changes in the plasma potassium concentration with time after intravenous salbutamol infusion are shown in the figure. The mean (SD) reduction in plasma potassium concentration was $1.48(0.5) \mathrm{mmol} / \mathrm{l}(\mathrm{n}=13, \mathrm{p}<0.001)$ and $1.64(0.5)$ $\mathrm{mmol} / \mathrm{l},(\mathrm{n}=9, \mathrm{p}<0.001)$ at 40 and 120 minutes, respectively, in the whole group after completion of the salbutamol infusion.

Changes were similar in the two subgroups of patients at both 40 and 120 minutes (figure). In those children who developed acute renal failure after cardiac surgery the salbutamol infusion resulted in no significant change in heart rate (135 (10) beats/minute before infusion compared with 139 (8) during infusion), mean arterial pressure (70 (5) $\mathrm{mmHg}$ compared with 68 (4)), or arterial oxygen saturation (92 (4)\% compared with 90 (3)\%), nor was there a need to increase the inotropic support during the period of the study.

\section{Discussion}

The definitive treatment of hyperkalaemia in renal

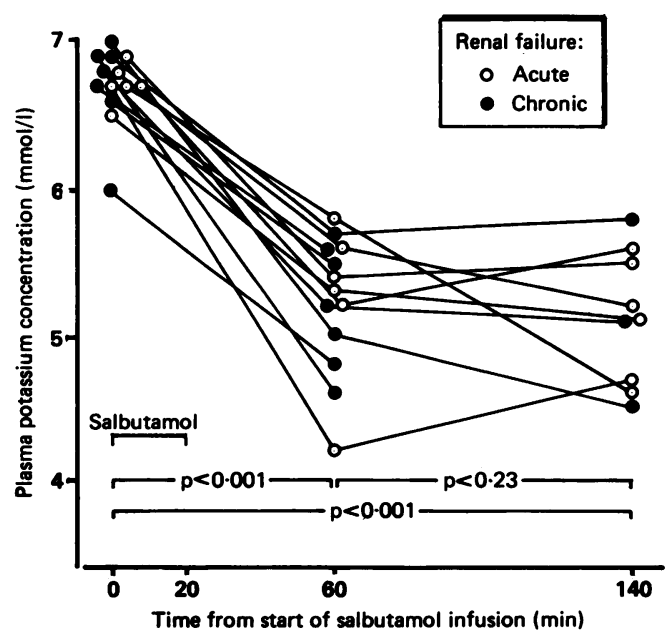

Plasma potassium concentrations at the start of infusion of intravenous salbutamol and at 60 and 140 minutes later in children with acute and chronic renal failure. failure is to remove the excess potassium by dialysis, supplemented if necessary by ion exchange resins. It is often necessary, however, to 'buy time' for these treatments to work by inducing a shift of potassium from the extracellular to the intracellular space. This can be achieved by the intravenous administration of sodium bicarbonate, or dextrose and insulin, and $\beta$ adrenergic stimulation also lowers the extracellular potassium concentration in this way. 45

Recent work, however, has suggested that bicarbonate alone is slow and limited in effect, ${ }^{6}$ and there is a high incidence of hypoglycaemia associated with the use of dextrose and insulin causing some physicians to advocate the use of dextrose alone. ${ }^{6}$

$\beta_{2}$ Adrenergic stimulation is known to promote extrarenal potassium uptake ${ }^{4}$ : we have used intravenous salbutamol, a $\beta_{2}$ agonist to produce this effect. Salbutamol acts by binding to the $\beta_{2}$ adrenergic receptors in the liver and muscle cell membranes. This then stimulates the enzyme adenylate cyclase, which increases the conversion of ATP to 3'5' cyclic AMP. This in turn acts on the sodium/potassium ATPase pump and facilities intracellular potassium uptake. ${ }^{4}$

Stemmer et al found that nebulised salbutamol was ineffective in promoting extrarenal potassium uptake in patients with end stage renal failure, but we found that an intravenous infusion of salbutamol was as effective in patients with acute on chronic renal failure as in those with acute renal failure after cardiac surgery despite the different ages and different degrees of severity of renal failure within the two groups.

Lens et al have recently shown that salbutamol given intravenously was as effective as dextrose and insulin in producing a reduction in the plasma potassium concentration in patients with chronic renal failure and it had no side effects: they also showed the effects of salbutamol given intravenously and of dextrose and insulin were additive. $^{3}$

We have shown that hyperkalaemia can effectively be reduced by one intravenous dose of salbutamol $(4 \mu \mathrm{g} / \mathrm{kg})$ given at a constant rate over 20 minutes. The effect lasts for at least 120 minutes after the end of the infusion allowing time for dialysis to be instituted if appropriate. The treatment is safe and avoids the risk of the hypoglycaemia that is caused by the use of dextrose and insulin in infants and small children. We now recommend salbutamol infusion as the first treatment of choice in children with dangerous hyperkalaemia; it can be combined with bicarbonate, ion exchange resins, and dextrose and insulin if necessary.

We thank the following for their permission to report their patients: Professor MJ Tynan, Professor C Chantler, Dr EJ patients: Professor MJ Tynan, Professor

1 Rolf Smith S, Kendall MJ. Inhaled bronchodilators and hypokalaemia. Lancet 1983 ;ii:218.

2 Wang $P$, Clausen T. Treatment of attacks in hyperkalaemic familial periodic paralysis by inhalation of salbutamol. Lancet 1976;i:221-3.

3 Lens XM, Montoliu J, Cases A, Campistol JM, Revert L. Treatment of hyperkalaemia in renal failure: insulin Nephrol Dial Transplant 1989;4.228 32 .

4 Rosa RM. Silva P, Young JB, et al. Adrenergic modulation of extrarenal potassium disposal. $N$ Engl $\mathscr{f}$ Med 1980;302: 431-4.

5 Stemmer CL, Perez GO, Oster JR. Impairment of $\beta$ 2adrenoreceptor-stimulated potassium uptake in end stage adrenoreceptor-stimulated potassium uptake in
renal disease. $\mathcal{F}$ Clin Pharmacol 1987;27:628-31.

6 Blumberg A, Wiedmann P, Shaw S, Gnadinger M. Effect of various therapeutic approaches on plasma potassium and various therapeutic approaches on plasma potassium and
major regulating factors in terminal renal failure. $A m \mathcal{F}$ Med 1988;85:507-12. 